\title{
Creation of a Metric for Faculty Effort in Teaching in the Veterinary Curriculum
}

\author{
Margaret V. Root Kustritz $\boldsymbol{\square}$ Laura K. Molgaard a Erin Malone
}

\begin{abstract}
A teaching-effort metric was generated using information from health sciences literature and self-reported data from faculty members. This metric was used to verify faculty effort based on teaching assignments, to equalize teaching between faculty members within disciplines, and to help faculty members understand the ramifications of new teaching opportunities on their overall effort.
\end{abstract}

Key words: employment, teaching, effort

Faculty effort at most schools is split into service, research, and teaching, with sub-categories of outreach, administrative work, and other forms of scholarly activity at some institutions. In veterinary medicine, faculty effort in clinical service is easily defined by number of cases seen or appointment times available; research by number of grants written or awarded or number of publications; scholarly activity and professional service by demonstration of manuscripts reviewed, book chapters written, or committee work; and outreach by number of continuing education talks given or projects in community service. Teaching effort has traditionally been more difficult to pinpoint. Some of the concerns include inability to completely separate clinical teaching from clinical service, especially in the common apprenticeship model, and variation in effort in didactic teaching due to factors outside of the discipline itself. These include type of student (undergraduate versus graduate or professional), number of students in the class, number of times the course has been taught in its current format, need to incorporate proposed or mandated changes in course format or content, variable presence of teaching assistants, and teaching methodology (passive versus active learning). Other considerations include the great variability in time required for different individuals to develop or prepare for the teaching of a course, to create and grade assessments and provide feedback to students, and to use technology to support instruction.

As part of a larger university effort, the authors' institution had undertaken a cost-saving exercise in which teaching, research, service, and operational efficiency were evaluated by groups of faculty and administrators and recommendations made. At the authors' institution, as at many institutions, teaching effort is self-defined and therefore not a reflection of the actual number of hours involved in teaching in all circumstances. It became clear through the review process described above that the college would benefit from creating a consistent metric that would be applied to all teaching faculty. This would permit the college to determine needed teaching effort and to staff accordingly. This article describes the creation and early implementation of such a metric.

Information in the literature that was used to create an effort matrix for teaching included workload logs and metadata pulled from university-wide systems that track all aspects of faculty work. ${ }^{1,2}$ Multipliers described in the literature for various kinds of work vary greatly, making it clear that there are many ways in which one may approach this problem. For the creation of this metric, information from the literature and information selfreported by faculty members was used to create a metric with appropriate multipliers to recognize average effort, including varying effort from when a class is created to when it is offered in later iterations, and varying expertise of teaching faculty. ${ }^{1-3}$ Data self-reported in each category were averaged, and the multiplier was determined as the mean plus two standard deviations. Averaged values were used to incorporate varying methods for determination of multipliers. Values were averaged by category, and that overall mean value for each category was then used as the multiplier. The metric is shown in Box 1.

Didactic teaching is recognized as the contact hours spent in lecture or facilitation of small group activities and contact hours spent in laboratory, on experiential activities, or on field trips. Online teaching varies from faceto-face teaching, with comparisons of the two formats varying as well. ${ }^{4,5}$ Creation of online modules entails significant effort, but updating those materials has been demonstrated to take less effort than face-to-face teaching, and workload for online teaching is much more variable within the course than it is for face-to-face teaching. ${ }^{4,5} \mathrm{In}$ this metric, clinical teaching is split into clinical roundswhich include both topic rounds (requiring preparation) and case-based rounds (requiring little to no preparation)-and facilitated case management, defined as the time spent working with students while managing a case. Finally, effort was assigned for mentoring individual 
Box I: Faculty effort metric $(\mathrm{CH}=$ contact hours $)$

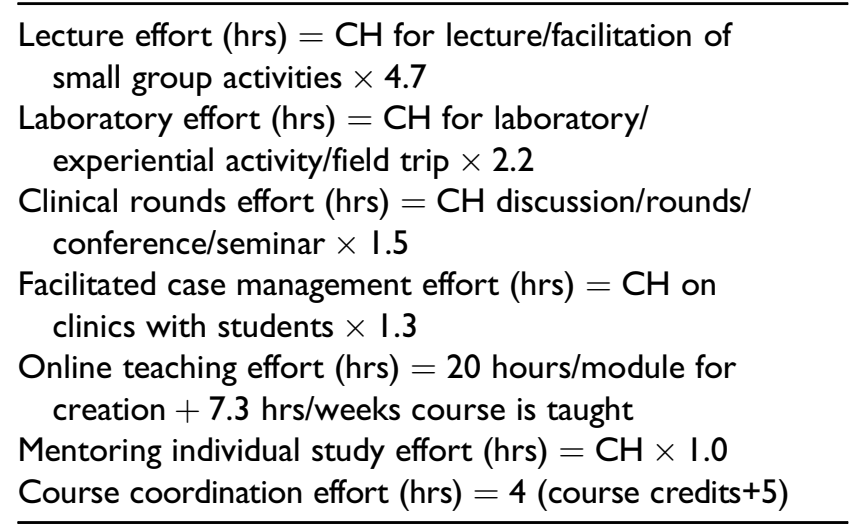

students, as may happen within a directed study, and for course coordination. The metric refers to faculty members only; there are no teaching assistants employed in the Doctor of Veterinary Medicine (DVM) curriculum at the authors' institution. The intent was that this metric would be used to verify teaching effort on the part of individual faculty members, to appropriately apportion teaching between faculty members within disciplines or sections, and to guide faculty members in intended changes in teaching effort. The leadership group in the college approved the metric.

Using the metric, faculty effort is defined in hours by adding the appropriate types of teaching for a given faculty member or discipline. For example, a faculty member that provides 15 contact hours of facilitated small group work and 45 hours of laboratory in a year and coordinates one 5-credit course, and who takes 4 weeks of vacation time, would have the following effort: (15)(4.7) + $(45)(2.2)+(4)(5+5)=158.7 \mathrm{hr} / 1,920 \mathrm{hr}=8.3 \%$ teaching effort. The authors have used the metric in this way to verify faculty effort at the time of merit review as a basis to justify assignment of either more or less teaching to faculty members with great discrepancy between allocated and calculated effort.

The metric has also been used to assess required teaching effort in a given discipline and to determine how that effort is best split between the faculty members in that discipline, recognizing the need for more junior faculty members to gain teaching experience and the varying effort in service and research among faculty in a given discipline. For example, if there are 62 hours of lecture or small group work and 24 hours of laboratory in a given discipline, that is $17.9 \%$ total effort in that discipline that could then be split logically between the faculty members in that group. The authors have used the metric in this way to appropriately apportion faculty effort in anesthesia and other disciplines teaching in the DVM curriculum.

Finally, the metric has been used to help faculty members gauge possible changes in their teaching, for instance, when being asked to take on the role of course coordinator in a new course or to significantly change an existing course. As an example, let us say a faculty member with
$20 \%$ teaching effort is asked to take on an independent study student with whom he or she would work for eight hours per week for one month. That would be an increase in effort of $1.6 \%$. The faculty member could then decide to absorb the change, having determined that it is small enough, or decide to talk to the department chair about decreasing effort in another area. The authors have used the metric in this way to help faculty members think through taking on another resident, offering a new elective, or considering how best to structure their teaching across the academic year.

Despite approval by college leadership, the metric was used as described by administrators in only one of the three departments in the authors' institution, specifically the small animal clinical department (Veterinary Clinical Sciences [VCS]). The large animal clinical department (Veterinary Population Medicine [VPM]) adopted a variant of this metric, using self-reported faculty hours to create different multipliers. The VPM department chose not to use the collegiate metric because they were comfortable with the metric they had designed. The multipliers used in their metric were included in the calculations for the collegiate metric and ended up being very similar. They did not include all the categories that are in the collegiate metric because they did not have faculty undertaking those tasks. The basic sciences department (Veterinary Biomedical Sciences [VBS]) employs few faculty members with significant didactic teaching effort and none with clinical teaching effort. The VBS department chair did not feel that the collegiate metric met the specific needs of faculty whose teaching is largely focused on mentoring of graduate students and post-doctoral fellows. Faculty members in VBS who appear to have over- or underrepresented time spent teaching according to self-reported hours are spoken to directly and their hours adjusted after discussion. The college centers (e.g., the Center for Animal Health and Food Safety), which were not included in the original discussions as their faculty function outside of the DVM curriculum, have used this metric to verify faculty effort and to budget appropriately for teaching expenses. The authors have provided this metric to several other schools of veterinary medicine that have struggled to create something similar and were desirous of using a metric based on the literature. The authors intend to continue to work with administrators to promote consistent application of the metric, thereby ensuring fairness between departments in the assessment of faculty effort.

There is great variability in how institutions calculate faculty effort in teaching and determine teaching expectations. ${ }^{3}$ Some faculty members in professional programs resist the idea of calculating teaching effort, as it appears too much like "punching the clock." Conversely, faculty members in veterinary medicine and other health sciences often complain that effort should not be predicated on a 40-hour work week, since they are required to see cases and do research while at work and so end up doing their teaching jobs on their own time. Other concerns include faculty members not being credited appropriately, especially for online work, and the use of multipliers that are 
averages, suggesting that no calculation accounts for the significant time and effort required in rethinking a course or program. ${ }^{6}$ Not included in this metric is the time spent learning new skills that will be used in teaching, including the use of teaching technologies and the time spent working with colleagues to understand what else is offered in the curriculum or to ensure optimal vertical and horizontal integration of content across the curriculum. This metric also does not include any measure of teaching quality. Administrators must bear these concerns in mind when using a metric such as this one with dedicated faculty members to ensure that use of the metric is supportive and reflective of faculty effort and collegiate needs. Collegiate administrators would benefit from research documenting accuracy of multipliers used as a true reflection of faculty effort.

\section{REFERENCES}

1 Crawford ME, Laing G, Linwood M, et al. A formula for calculating faculty workload. J Nurs Educ. 1983;22(7):285-6. Medline:6313570

2 Hashim RH, Hamid JA, Selamat MH, et al. Using algorithmic taxonomy to evaluate lecturer workload. J Know Mgmt Prac. 2006;7:1-17.

3 Mupinga DM, Maughan GR. Web-based instruction and community college faculty workload. Coll Teach. 2008;56(1):17-21. http://dx.doi.org/10.3200/ CTCH.56.1.17-22.

4 Tomei L. The impact of online teaching on faculty load. J Technol Teach Educ. 2006;14:531-41.
5 Andersen KM, Avery MD. Faculty teaching time: a comparison of web-based and face-to-face graduate nursing courses. Int J Nurs Educ Scholarsh. 2008;5(1):112. http://dx.doi.org/10.2202/1548-923X.1539. Medline:18241197

6 Cohen MZ, Hickey JV, Upchurch SL. Faculty workload calculation. Nurs Outlook. 2009;57(1):50-9. http://dx.doi.org/10.1016/j.outlook.2008.07.004. Medline:19150267

\section{AUTHOR INFORMATION}

Margaret V. Root Kustritz, DVM, PhD, DACT, is Professor of Theriogenology and Assistant Dean of Education, Department of Veterinary Clinical Sciences, University of Minnesota College of Veterinary Medicine, St. Paul, MN 55108 USA.

E-mail: rootk00I@umn.edu. Dr. Root's research interests include determination of optimal age for gonadectomy of dogs and cats and innovative teaching strategies.

Laura K. Molgaard, DVM, is Associate Dean of Academic and Student Affairs, Department of Veterinary Clinical Sciences, University of Minnesota College of Veterinary Medicine, St. Paul, MN 55108 USA. Dr. Molgaard's research interests include selection for and development of non-technical competencies, technology enhanced learning, and outcomes assessment.

Erin Malone, DVM, PhD, DACVS, is Professor of Large Animal Surgery and Curriculum Coordinator, Department of Veterinary Population Medicine, University of Minnesota College of Veterinary Medicine, St. Paul, MN 55I 08 USA. Dr. Malone's research interests include evaluation of teaching methodologies to enhance retention. 